\title{
Application of a Neural Network Model for Prediction of Wear Properties of Ultrahigh Molecular Weight Polyethylene Composites
}

\author{
Halil Ibrahim Kurt and Murat Oduncuoglu \\ Technical Sciences, University of Gaziantep, 27310 Gaziantep, Turkey \\ Correspondence should be addressed to Halil Ibrahim Kurt; hiakurt@gmail.com
}

Received 7 December 2014; Revised 25 May 2015; Accepted 31 May 2015

Academic Editor: Togay Ozbakkaloglu

Copyright (C) 2015 H. I. Kurt and M. Oduncuoglu. This is an open access article distributed under the Creative Commons Attribution License, which permits unrestricted use, distribution, and reproduction in any medium, provided the original work is properly cited.

\begin{abstract}
In the current study, the effect of applied load, sliding speed, and type and weight percentages of reinforcements on the wear properties of ultrahigh molecular weight polyethylene (UHMWPE) was theoretically studied. The extensive experimental results were taken from literature and modeled with artificial neural network (ANN). The feed forward (FF) back-propagation (BP) neural network (NN) was used to predict the dry sliding wear behavior of UHMWPE composites. Eleven input vectors were used in the construction of the proposed NN. The carbon nanotube (CNT), carbon fiber (CF), graphene oxide (GO), and wollastonite additives are the main input parameters and the volume loss is the output parameter for the developed NN. It was observed that the sliding speed and applied load have a stronger effect on the volume loss of UHMWPE composites in comparison to other input parameters. The proper condition for achieving the desired wear behaviors of UHMWPE by tailoring the weight percentage and reinforcement particle size and composition was presented. The proposed NN model and the derived explicit form of mathematical formulation show good agreement with test results and can be used to predict the volume loss of UHMWPE composites.
\end{abstract}

\section{Introduction}

Polymers have high elasticity, good process ability, and reasonable strength, so they can be called multifunctional materials. Polymer-based composites are widely used in various applications and many fields, including microelectronics, biomedical engineering, electrical devices, and filtration [15]. Polymer-based nanocomposites formed by adding a small amount of micro- and nanoparticles to the matrix have created great interest in engineering and science. Composites with nanoparticles display superior thermal, electrical, and mechanical properties [6-8]. The properties of the materials have been improved by adding fillers such as graphite nanosheets, CNTs, and boron nitride (BN) to polymer matrices [9-11].

UHMWPE is widely used as the matrix material in the production of polymer matrix nanocomposites. UHMWPE has so many excellent properties such as being light in weight, corrosion resistant, biocompatible, and self-lubricant. Due to these special properties and several advantages, it has gained worldwide acceptance and is widely used in military, industrial, medical, and consumer applications involving wear and friction $[12,13]$. UHMWPE is a complicated material, meaning that several factors can be responsible for wear. One method of increasing the wear resistance of UHMWPE is the adding of fiber fillers and nano- and microparticles in the composition and they are called UHMWPE composites. Theoretically, polymers can be strengthened by molecular alignment of the material. When sliding loads are applied to a specimen of UHMWPE, the molecular chains begin to straighten, be untangled, and align in load direction, and the strength tends to increase in this direction. UHMWPE composites can also be further engineered at a micro- or nanometer length scale by blending polymer powder resin with micro- or nanoparticles and fibers before consolidation. UHMWPE composites were reinforced by $\mathrm{TiO}_{2}$, CNT, kaolin, CF, hydroxyapatite, $\mathrm{Al}_{2} \mathrm{O}_{3}$, zirconium particles [14-18], and so forth. The works have demonstrated that 
the addition of optimum amount of nano- and microfibers and ceramic particles into UHMWPE would significantly affect the wear rate under sliding wear conditions.

Recently, the material properties with their own characteristics, applications, advantages, and limitations are important factors for designers and materials engineers. Due to UHMWPE's complex behaviors, finding an appropriate model for determining the wear properties of UHMWPE can be challenging. The effect of type and weight percentage of fibers and particles in composition and one of the operation parameters such as applied load and sliding speed on wear behavior of UHMWPE was investigated separately. In selecting additive materials, type and percentage for an application are important. The experimental determination of additives for desired wear behavior of UHMWPE composites is cost- and time-consuming. ANN modeling has been used to minimize the experimental study and predict the wear characteristics to establish a correlation between the wear properties and operation parameters of UHMWPE composites. Therefore, the main aim is to determine and understand the effect of type, size, and weight percentage of different reinforcement and variables in operation condition on dry sliding wear properties of UHMWPE composites.

\section{Neural Network}

The ANNs are a methodology in different applications of materials including prediction of tribological and mechanical properties and were used by many researchers [19-24]. Venkata Rao et al. [25] used ANN to predict surface roughness, tool wear, and amplitude of work piece vibration. They reported that the neural network can help in the selection of proper cutting parameters to reduce tool vibration and tool wear and reduce surface roughness. Gyurova and Friedrich [26] for the prediction of sliding friction and wear properties of polymer composites used ANN and stated that the prediction profiles for the characteristic tribological properties of the ANN exhibited very good agreement with the measured results. Li et al. [27] modeled the sliding wear resistance of the Ni-TiN coatings by using ANN. They explained that the proposed ANN model shows an error of approximately $4.2 \%$ and can effectively predict sliding wear resistance of $\mathrm{Ni}-\mathrm{TiN}$ nanocomposite coatings.

An ANN can be defined as a massively parallel distributed processor storing experiential knowledge and making it available for use [28]. $\mathrm{NN}$ is a computational framework that is inspired by biological neural systems. Figure 1 shows the input layer, hidden layer, and the output layer in $\mathrm{NN}$ system [29]. It consists of a number of interconnected simple processing units called artificial neurons. The basic structure of an artificial neuron was shown in Figure 2. In ANN modeling, the networks include artificial neurons that consist of three main components, namely, weights, bias, and transfer function.

Each neuron receives inputs, attached with a weight $w_{i}$, which shows the connection strength for that input for each connection. Each input is multiplied by the corresponding weight of the neuron connection. Next, a bias $\left(b_{i}\right)$ value is

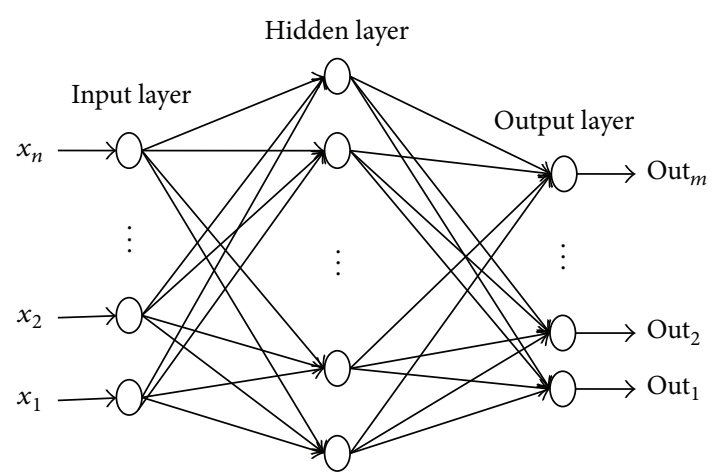

FIgURE 1: A typical neural network image.

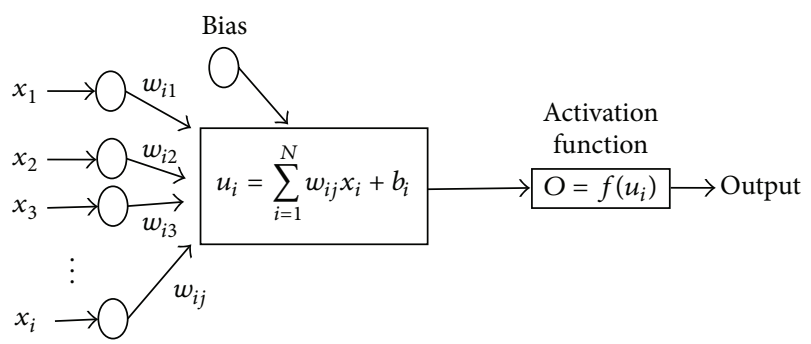

Figure 2: The basic structure of an artificial neuron [43].

added to the summation of inputs and corresponding weights $(u)$ according to the following equation:

$$
u_{i}=\sum_{j=1}^{H} w_{i j} x_{j}+b_{i} .
$$

The summation $u_{i}$ is converted as output with an activation (transfer) function, $F\left(u_{i}\right)$, yielding a value called the unit's "activation," as in the following formula:

$$
O=f\left(u_{i}\right) .
$$

\section{Results and Discussion}

NNs are commonly classified according to training algorithms (supervised and unsupervised) and network topology (feedback and feed forward) [30]. BP learning algorithm (Levenberg-Marquardt (Trainlm)) is the most popular and effective supervised learning method used in this study [31, 32]. Sigmoid function, which joins curvilinear, linear, and constant behavior depending on the values of the input, is commonly used as transfer function in NNs $[33,34]$. The weight loss of the composites was converted to volume loss, $V$, by dividing it with the specific composite density by the following formula [35]:

$$
V=\frac{\left(W_{1}-W_{2}\right)}{d},
$$

where $W_{1,2}$ is the weight loss before and after wear test, respectively, and $d$ is the density of the composites. In an ANN model, each of the input and output variables was scaled 
to fall into a range of 0 to 1 , using the following scaling formula:

$$
x_{N}=\frac{x-x_{\min }}{x_{\max }-x_{\min }},
$$

where $x_{N}$ is the normalized value of the parameter $x$ and $x_{\max }$ and $x_{\min }$ are the maximum and minimum values of this parameter, respectively. Output values resulted from ANN also in the range $[0,1]$ and transformed to its equivalent values based on reverse method of normalization technique [36]. The unnormalized method is as

$$
x=x_{N}\left(x_{\max }-x_{\min }\right)+x_{\min }
$$

An extensive literature survey has been performed for collecting the experimental data. Two main processing phases of NN include training and testing. The training process is the adjustment of weights and biases in order to obtain the output through applying a proper method. Hence, the experimental results were divided in two sets, training and testing sets. The training and testing data were randomly selected among experimental results as shown in the Appendix. The input (independent) variables are UHMWPE (wt.\%), $\mathrm{ZnO}$ (wt.\%), zeolite (wt.\%), CNT (wt.\%), CF (wt.\%), GO (wt.\%), wollastonite (wt.\%), size of $\mathrm{ZnO}(\mu \mathrm{m})$ and zeolite $(\mu \mathrm{m})$, load $(\mathrm{N})$, and sliding speed $(\mathrm{m} / \mathrm{s})$, respectively. The output or dependent variable is volume loss $\left(\mathrm{mm}^{3}\right)$.

The network architecture and parameters affect the performance of NN. One of the most important duties in NN works is the determination of the numbers of layers and neurons in the hidden layers. In other words, the ANN parameters, such as the number of neurons in the input, network architecture, hidden layer, output layer, learning algorithm, and transfer function, are to be selected for developing an ANN model. There is no well-defined procedure to find the optimal parameter settings and network architecture. The trial and error approach with various numbers of neurons in one hidden layer was used to determine the number of neurons. It was observed that the optimal NN architecture with logistic sigmoid transfer function was $11-12-1 \mathrm{NN}$ architecture. Figure 3 shows the optimal architecture of NN. In the present study, the NN model consists of three layers, which comprises an input layer, a hidden layer, and an output layer.

The performance of $\mathrm{NN}$ was evaluated by the correlation coefficient $(R)$ as in the following expression:

$$
R=\frac{\operatorname{cov}\left(y_{t}, y_{t}^{\prime}\right)}{\sqrt{\operatorname{var}\left(y_{t}\right) \cdot \operatorname{var}\left(y_{t}^{\prime}\right)}}
$$

Mean absolute error (MAE) and mean square error (MSE) were used as error evaluation criteria in order to

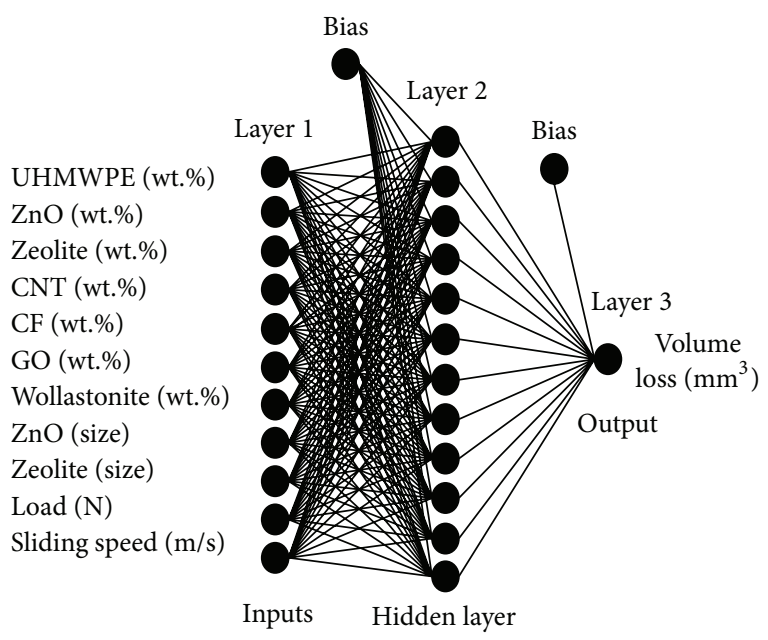

FIGURE 3: Optimal NN selection process.

TABLE 1: Statistical parameters of training and testing sets.

\begin{tabular}{lccc}
\hline Datasets & $R$ & MAE & MSE \\
\hline Training set & 0.9400 & 3.63 & 0.389 \\
Testing set & 0.9176 & 4.07 & 0.412 \\
\hline
\end{tabular}

facilitate the comparisons between predicted values and desired values according to the following equations:

$$
\begin{aligned}
& \text { MAE }=\frac{1}{N} \sum_{i=1}^{N}\left|t_{i}-\widehat{t}_{i}\right|, \\
& \operatorname{MSE}=\left(\frac{1}{N} \sum_{i=1}^{N}\left|t_{i}-\widehat{t}_{i}\right|\right)^{2},
\end{aligned}
$$

where $N$ is the total number of the datasets and $t_{i}$ and $\widehat{t}_{i}$ are the experimental value and predicted output value from the neural network model for a given input, respectively.

The statistical data for the training and testing sets were shown in Table 1. The correlation of NN model with the experimental data for these sets was also shown in Figures 4 and 5.

The correlation of coefficients in training and testing sets is 0.9400 and 0.9176 which means that the performance of network model is acceptable. MAE and MSE values of volume loss are 3.63 and 0.389 for training set and 4.07 and 0.412 for testing set. If the MSE reaches zero, the performance of model is regarded as being excellent [37]. Comparison between the test and predicted values shows that the prediction of the proposed $\mathrm{NN}$ model is in good agreement with the experimental data and all the errors are within acceptable ranges.

$R^{2}$ values of training and testing sets are 0.8837 and 0.842 , respectively. $R^{2}$ value compares the accuracy of the model to the accuracy of a trivial assessment model. A high $R^{2}$ value $\left(R^{2}=1\right)$ tells that all points lie exactly on the curve with no scatter and the results have the perfect correlation. It is clear that all the values are higher than 0.84 . 


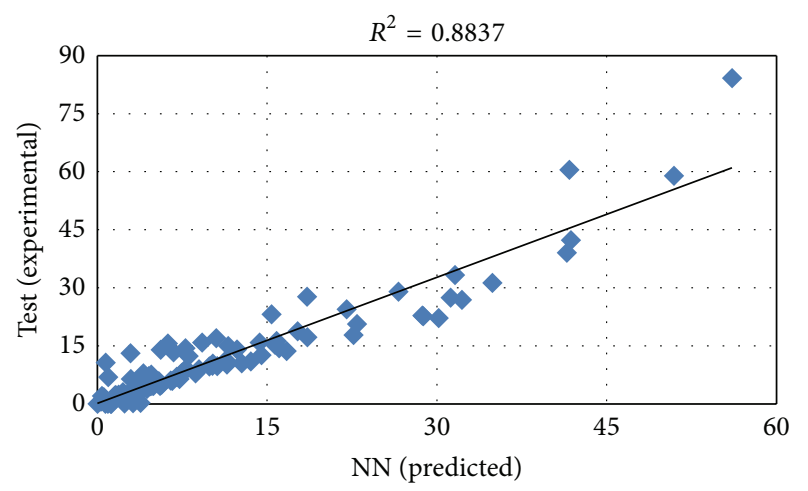

FIGURE 4: Correlation of NN and experimental data for training set.

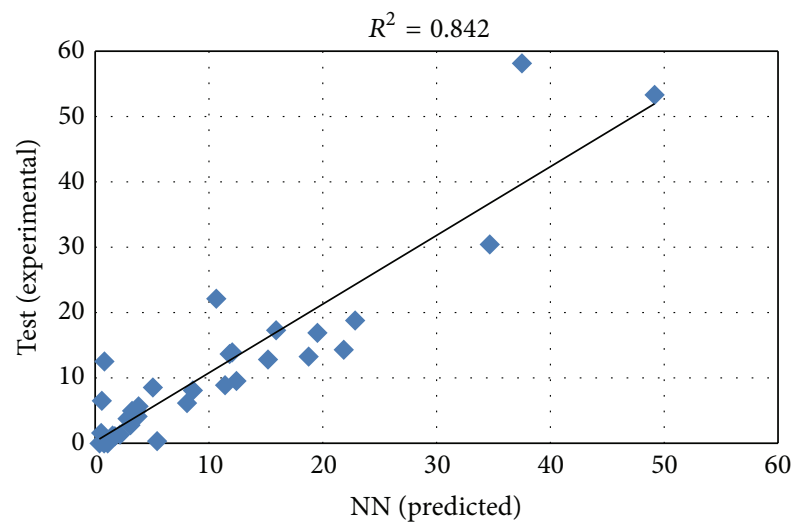

Figure 5: Correlation of NN and experimental data for testing set.

The wear rate of the composites is strongly influenced by many factors, such as the shape and content of reinforcement, operating conditions, the morphologies of surfaces, physical morphology between the matrix material and reinforcement, the bond strength at the matrix/reinforcement interface, and homogeneous distribution of reinforcement [38, 39]. It is difficult to find the effect of each factor on the wear volume loss of the composites and it needs extensive studies. In the current work, the operating parameters and weight percentages and sizes of reinforcement were quantified. Nevertheless, $R$ and $R^{2}$ values of training set indicate that the learning ability of NN is well enough (Table 1 and Figure 4). The effects of the other parameters can be investigated in order to increase the prediction rate of the proposed $\mathrm{NN}$ model. It was concluded that the proposed NN model can predict the volume loss of UHMWPE composites containing different particles with size and weight percentages with high accuracy and reliability.

The sensitivity of wear volume loss of UHMWPE composites of each input variable from the minimum to the maximum was given in Figure 6. The sliding speed is an example of factors that can contribute to wear. Our theoretical results demonstrated that the sliding speed has the greatest effect on volume loss of UHMWPE among all input parameters. The different sliding speeds can result in different wear properties. The higher the loading speed is, the more the time UHMWPE will spend in the elastic deformation stage. It is clear that any change in sliding speed, load, UHMWPE

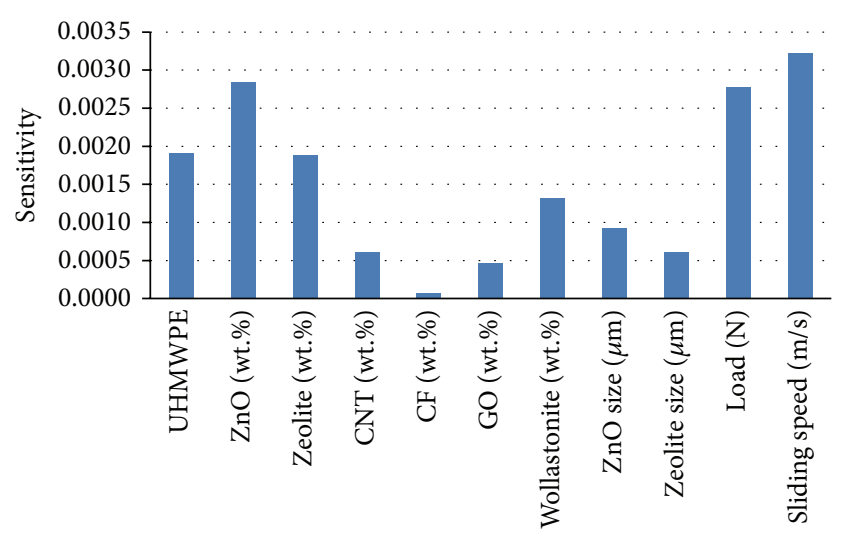

Input parameter

FIGURE 6: Sensitivity of input vectors.

(wt.\%), $\mathrm{ZnO}$ (wt.\%), and zeolite (wt.\%) will be affected by the volume loss of UHMWPE in comparison to all the other input parameters.

\section{Formulation of NN Model}

The main focus is to obtain the explicit formulation of the volume loss as a function of input variables under limited conditions. The ANN models emerged as good candidates for mathematical wear models due to their capabilities in nonlinear behavior, learning from experimental data, and generalization [40]. Hutching's group [41] and Basavarajappa et al. [42] presented pioneering investigations of ANN techniques for predicting tribological parameters.

As a result, the wear behavior under various parameters was investigated to predict and analyze the relationship between the reinforcements and volume loss of UHMWPE composites. The volume loss $(X)$ was determined by using the formula

$$
X=84.185617 *\left(\frac{1}{1+e^{-v}}\right)+0.212915,
$$

where the parameters are

$$
\begin{aligned}
v= & (-2.1888) *\left(\frac{1}{1+e^{-u 1}}\right)+(1.5322) \\
& *\left(\frac{1}{1+e^{-u 2}}\right)+(5.8748) *\left(\frac{1}{1+e^{-u 3}}\right) \\
& +(4.2619) *\left(\frac{1}{1+e^{-u 4}}\right)+(-0.6620) \\
& *\left(\frac{1}{1+e^{-u 5}}\right)+(-2.9341) *\left(\frac{1}{1+e^{-u 6}}\right) \\
& +(-0.6885) *\left(\frac{1}{1+e^{-u 7}}\right)+(-0.6696) \\
& *\left(\frac{1}{1+e^{-u 8}}\right)+(0.9414) *\left(\frac{1}{1+e^{-u 9}}\right) \\
& +(-5.8760) *\left(\frac{1}{1+e^{-u 10}}\right)+(-6.0830) \\
& *\left(\frac{1}{1+e^{-u 11}}\right)+(-2.7599) *\left(\frac{1}{1+e^{-u 12}}\right) \\
& +(-0.7807),
\end{aligned}
$$




$$
\begin{aligned}
& u 1=(-0.7182 * A 1)+(-0.5842 * A 2) \\
& +(-0.7211 * A 3)+(0.5435 * A 4) \\
& +(0.7793 * A 5)+(-0.1909 * A 6) \\
& +(0.4002 * A 7)+(0.8474 * A 8) \\
& +(-0.7288 * A 9)+(-0.2069 * A 10) \\
& +(-1.9995 * A 11)+(-0.0394) \text {, } \\
& u 2=(0.7896 * A 1)+(-0.2539 * A 2) \\
& +(0.1801 * A 3)+(-0.1505 * A 4) \\
& +(0.0765 * A 5)+(-0.2878 * A 6) \\
& +(0.1697 * A 7)+(0.5636 * A 8) \\
& +(-0.0203 * A 9)+(-0.8914 * A 10) \\
& +(1.9869 * A 11)+(-0.1818) \text {, } \\
& u 3=(-2.3087 * A 1)+(0.4084 * A 2) \\
& +(0.4903 * A 3)+(-0.8781 * A 4) \\
& +(-1.3043 * A 5)+(-0.9548 * A 6) \\
& +(-0.6670 * A 7)+(2.7410 * A 8) \\
& +(-2.1091 * A 9)+(3.2012 * A 10) \\
& +(1.8193 * A 11)+(-3.4212), \\
& u 4=(2.0533 * A 1)+(-3.2323 * A 2) \\
& +(0.7227 * A 3)+(0.0295 * A 4) \\
& +(-0.5151 * A 5)+(0.0588 * A 6) \\
& +(-0.7574 * A 7)+(-0.2123 * A 8) \\
& +(-0.6447 * A 9)+(4.5743 * A 10) \\
& +(0.5803 * A 11)+(-0.8036) \text {, } \\
& u 5=(0.3405 * A 1)+(-0.2333 * A 2) \\
& +(0.2794 * A 3)+(0.3565 * A 4) \\
& +(0.4379 * A 5)+(-0.0345 * A 6) \\
& +(-0.0986 * A 7)+(0.0275 * A 8) \\
& +(0.6663 * A 9)+(-0.3537 * A 10) \\
& +(-0.4749 * A 11)+(-0.2079) \text {, } \\
& u 6=(0.5510 * A 1)+(-2.2037 * A 2) \\
& +(0.1234 * A 3)+(0.3718 * A 4) \\
& +(0.3239 * A 5)+(0.5667 * A 6) \\
& +(-0.2435 * A 7)+(-0.7447 * A 8) \\
& +(0.6221 * A 9)+(-0.2125 * A 10) \\
& +(-0.3791 * A 11)+(0.1155) \text {, } \\
& u 8=(0.7380 * A 1)+(0.0758 * A 2)+(0.4082 * A 3) \\
& +(-0.0235 * A 4)+(0.2302 * A 5) \\
& +(-0.1718 * A 6)+(0.0265 * A 7) \\
& +(1.2521 * A 8)+(-0.4670 * A 9) \\
& +(1.0054 * A 10)+(0.8061 * A 11) \\
& +(0.5412) \text {, } \\
& u 9=(0.2707 * A 1)+(0.7648 * A 2)+(0.2012 * A 3) \\
& +(-0.4448 * A 4)+(-0.5107 * A 5) \\
& +(-0.2796 * A 6)+(-0.1827 * A 7) \\
& +(0.1138 * A 8)+(-0.6849 * A 9) \\
& +(0.4180 * A 10)+(0.2120 * A 11) \\
& +(-0.4322) \text {, } \\
& u 10=(-1.8196 * A 1)+(0.3943 * A 2) \\
& +(-0.3793 * A 3)+(-0.1015 * A 4) \\
& +(-0.6886 * A 5)+(-0.0171 * A 6) \\
& +(-0.0900 * A 7)+(2.7289 * A 8) \\
& +(-0.3999 * A 9)+(-6.8627 * A 10) \\
& +(1.5364 * A 11)+(-1.7102), \\
& u 11=(-0.0124 * A 1)+(-2.2261 * A 2) \\
& +(-0.5712 * A 3)+(0.1810 * A 4) \\
& +(0.7198 * A 5)+(-0.3316 * A 6) \\
& +(0.4865 * A 7)+(-0.8473 * A 8) \\
& +(-1.0742 * A 9)+(4.8908 * A 10) \\
& +(-1.9057 * A 11)+(-0.4736), \\
& u 12=(-0.1888 * A 1)+(-2.3874 * A 2) \\
& +(-0.1633 * A 3)+(0.2577 * A 4) \\
& +(0.4452 * A 5)+(0.0305 * A 6) \\
& +(0.0384 * A 7)+(-0.9836 * A 8) \\
& +(0.0058 * A 9)+(-2.1195 * A 10) \\
& +(2.0152 * A 11)+(-0.8806),
\end{aligned}
$$$$
+(1.1467 * A 9)+(-2.4374 * A 10)
$$$$
+(0.0093 * A 11)+(0.0879) \text {, }
$$$$
u 7=(0.1883 * A 1)+(-0.4882 * A 2)
$$$$
+(0.0982 * A 3)+(0.1593 * A 4)
$$$$
+(-0.0599 * A 5)+(0.5295 * A 6)
$$$$
+(0.3879 * A 7)+(-0.2778 * A 8)
$$

where $A 1, A 2, A 3, A 4, A 5, A 6, A 7, A 8, A 9, A 10$, and $A 11$ are normalized values of UHMWPE, $\mathrm{ZnO}$ (wt.\%), zeolite (wt.\%), CNT (wt.\%), CF (wt.\%), GO (wt.\%), wollastonite (wt.\%), size of $\mathrm{ZnO}$ and zeolite $(\mu \mathrm{m})$,load $(\mathrm{N})$, and sliding speed $(\mathrm{m} / \mathrm{s})$, respectively.

Using derived formulation, the wear volume loss of UHMWPE composite with the size of $1 \mu \mathrm{m}$ and $5 \mathrm{wt} . \% \mathrm{ZnO}$ 
TABLE 2: Dataset used NN model.

\begin{tabular}{|c|c|c|c|c|c|c|c|c|c|c|}
\hline Reference & UHMWPE & $\begin{array}{c}\mathrm{ZnO} \\
\text { (wt.\%) }\end{array}$ & $\begin{array}{l}\text { Zeolite } \\
\text { (wt.\%) }\end{array}$ & $\begin{array}{c}\text { CNT } \\
\text { (wt.\%) }\end{array}$ & $\begin{array}{c}\mathrm{CF} \\
\text { (wt.\%) }\end{array}$ & $\begin{array}{c}\mathrm{GO} \\
\text { (wt.\%) }\end{array}$ & $\begin{array}{c}\text { Wollastonite } \\
\text { (wt.\%) }\end{array}$ & $\begin{array}{c}\text { Load } \\
(\mathrm{N})\end{array}$ & $\begin{array}{c}\text { Sliding speed } \\
(\mathrm{m} / \mathrm{s})\end{array}$ & $\begin{array}{c}\text { Volume loss } \\
\left(\mathrm{mm}^{3}\right)\end{array}$ \\
\hline \multirow{46}{*}{$\begin{array}{l}\text { Chang et al. } \\
{[44]}\end{array}$} & 100 & - & - & - & - & - & - & 10 & 0,033 & 5,699 \\
\hline & 95 & 5 & - & - & - & - & - & 10 & 0,033 & 3,093 \\
\hline & 90 & 10 & - & - & - & - & - & 10 & 0,033 & 2,075 \\
\hline & 85 & 15 & - & - & - & - & - & 10 & 0,033 & 2,329 \\
\hline & 80 & 20 & - & - & - & - & - & 10 & 0,033 & 2,413 \\
\hline & 95 & 5 & - & - & - & - & - & 10 & 0,033 & 3,781 \\
\hline & 90 & 10 & - & - & - & - & - & 10 & 0,033 & 2,218 \\
\hline & 85 & 15 & - & - & - & - & - & 10 & 0,033 & 1,962 \\
\hline & 80 & 20 & - & - & - & - & - & 10 & 0,033 & 2,091 \\
\hline & 100 & - & - & - & - & - & - & 20 & 0,033 & 13,333 \\
\hline & 95 & 5 & - & - & - & - & - & 20 & 0,033 & 6,101 \\
\hline & 90 & 10 & - & - & - & - & - & 20 & 0,033 & 6,440 \\
\hline & 85 & 15 & - & - & - & - & - & 20 & 0,033 & 6,927 \\
\hline & 80 & 20 & - & - & - & - & - & 20 & 0,033 & 6,541 \\
\hline & 95 & 5 & - & - & - & - & - & 20 & 0,033 & 6,358 \\
\hline & 90 & 10 & - & - & - & - & - & 20 & 0,033 & 4,150 \\
\hline & 85 & 15 & - & - & - & - & - & 20 & 0,033 & 4,965 \\
\hline & 80 & 20 & - & - & - & - & - & 20 & 0,033 & 4,611 \\
\hline & 100 & - & - & - & - & - & - & 30 & 0,033 & 15,914 \\
\hline & 95 & 5 & - & - & - & - & - & 30 & 0,033 & 10,225 \\
\hline & 90 & 10 & - & - & - & - & - & 30 & 0,033 & 9,159 \\
\hline & 85 & 15 & - & - & - & - & - & 30 & 0,033 & 8,582 \\
\hline & 80 & 20 & - & - & - & - & - & 30 & 0,033 & 7,613 \\
\hline & 95 & 5 & - & - & - & - & - & 30 & 0,033 & 7,905 \\
\hline & 90 & 10 & - & - & - & - & - & 30 & 0,033 & 4,722 \\
\hline & 85 & 15 & - & - & - & - & - & 30 & 0,033 & 7,172 \\
\hline & 80 & 20 & - & - & - & - & - & 30 & 0,033 & 4,986 \\
\hline & 100 & - & - & - & - & - & - & 10 & 0,368 & 22,151 \\
\hline & 95 & 5 & - & - & - & - & - & 10 & 0,368 & 14,435 \\
\hline & 90 & 10 & - & - & - & - & - & 10 & 0,368 & 13,094 \\
\hline & 85 & 15 & - & - & - & - & - & 10 & 0,368 & 12,566 \\
\hline & 80 & 20 & - & - & - & - & - & 10 & 0,368 & 10,723 \\
\hline & 95 & 5 & - & - & - & - & - & 10 & 0,368 & 14,092 \\
\hline & 90 & 10 & - & - & - & - & - & 10 & 0,368 & 9,874 \\
\hline & 85 & 15 & - & - & - & - & - & 10 & 0,368 & 12,382 \\
\hline & 80 & 20 & - & - & - & - & - & 10 & 0,368 & 8,096 \\
\hline & 100 & - & - & - & - & - & - & 20 & 0,368 & 27,742 \\
\hline & 95 & 5 & - & - & - & - & - & 20 & 0,368 & 18,818 \\
\hline & 90 & 10 & - & - & - & - & - & 20 & 0,368 & 17,029 \\
\hline & 85 & 15 & - & - & - & - & - & 20 & 0,368 & 15,631 \\
\hline & 80 & 20 & - & - & - & - & - & 20 & 0,368 & 13,993 \\
\hline & 95 & 5 & - & - & - & - & - & 20 & 0,368 & 16,326 \\
\hline & 90 & 10 & - & - & - & - & - & 20 & 0,368 & 12,665 \\
\hline & 85 & 15 & - & - & - & - & - & 20 & 0,368 & 13,669 \\
\hline & 80 & 20 & - & - & - & - & - & 20 & 0,368 & 11,312 \\
\hline & 100 & - & - & - & - & - & - & 30 & 0,368 & 29,032 \\
\hline
\end{tabular}


TABLE 2: Continued.

\begin{tabular}{|c|c|c|c|c|c|c|c|c|c|c|}
\hline Reference & UHMWPE & $\begin{array}{c}\mathrm{ZnO} \\
\text { (wt.\%) }\end{array}$ & $\begin{array}{l}\text { Zeolite } \\
\text { (wt.\%) }\end{array}$ & $\begin{array}{l}\text { CNT } \\
\text { (wt.\%) }\end{array}$ & $\begin{array}{c}\mathrm{CF} \\
\text { (wt.\%) }\end{array}$ & $\begin{array}{c}\mathrm{GO} \\
\text { (wt.\%) }\end{array}$ & $\begin{array}{l}\text { Wollastonite } \\
\text { (wt.\%) }\end{array}$ & $\begin{array}{l}\text { Load } \\
(\mathrm{N})\end{array}$ & $\begin{array}{l}\text { Sliding speed } \\
(\mathrm{m} / \mathrm{s})\end{array}$ & $\begin{array}{l}\text { Volume loss } \\
\left(\mathrm{mm}^{3}\right)\end{array}$ \\
\hline & 95 & 5 & - & - & - & - & - & 30 & 0,368 & 22,255 \\
\hline & 90 & 10 & - & - & - & - & - & 30 & 0,368 & 17,816 \\
\hline & 85 & 15 & - & - & - & - & - & 30 & 0,368 & 17,347 \\
\hline & 80 & 20 & - & - & - & - & - & 30 & 0,368 & 15,923 \\
\hline & 95 & 5 & - & - & - & - & - & 30 & 0,368 & 17,271 \\
\hline & 90 & 10 & - & - & - & - & - & 30 & 0,368 & 13,309 \\
\hline & 85 & 15 & - & - & - & - & - & 30 & 0,368 & 15,324 \\
\hline & 80 & 20 & - & - & - & - & - & 30 & 0,368 & 12,867 \\
\hline & 100 & - & - & - & - & - & - & 10 & 1,022 & 23,226 \\
\hline & 95 & 5 & - & - & - & - & - & 10 & 1,022 & 14,435 \\
\hline & 90 & 10 & - & - & - & - & - & 10 & 1,022 & 13,952 \\
\hline & 85 & 15 & - & - & - & - & - & 10 & 1,022 & 10,482 \\
\hline & 80 & 20 & - & - & - & - & - & 10 & 1,022 & 9,543 \\
\hline & 95 & 5 & - & - & - & - & - & 10 & 1,022 & 14,350 \\
\hline & 90 & 10 & - & - & - & - & - & 10 & 1,022 & 13,666 \\
\hline & 85 & 15 & - & - & - & - & - & 10 & 1,022 & 15,018 \\
\hline & 80 & 20 & - & - & - & - & - & 10 & 1,022 & 9,704 \\
\hline & 100 & - & - & - & - & - & - & 20 & 1,022 & 27,527 \\
\hline & 95 & 5 & - & - & - & - & - & 20 & 1,022 & 31,277 \\
\hline & 90 & 10 & - & - & - & - & - & 20 & 1,022 & 22,682 \\
\hline & 85 & 15 & - & - & - & - & - & 20 & 1,022 & 20,657 \\
\hline & 80 & 20 & - & - & - & - & - & 20 & 1,022 & 18,818 \\
\hline & 95 & 5 & - & - & - & - & - & 20 & 1,022 & 26,895 \\
\hline & 90 & 10 & - & - & - & - & - & 20 & 1,022 & 22,825 \\
\hline & 85 & 15 & - & - & - & - & - & 20 & 1,022 & 24,458 \\
\hline & 80 & 20 & - & - & - & - & - & 20 & 1,022 & 16,942 \\
\hline & 100 & - & - & - & - & - & - & 30 & 1,022 & 53,333 \\
\hline & 95 & 5 & - & - & - & - & - & 30 & 1,022 & 84,207 \\
\hline & 90 & 10 & - & - & - & - & - & 30 & 1,022 & 58,958 \\
\hline & 85 & 15 & - & - & - & - & - & 30 & 1,022 & 60,500 \\
\hline & 80 & 20 & - & - & - & - & - & 30 & 1,022 & 58,171 \\
\hline & 95 & 5 & - & - & - & - & - & 30 & 1,022 & 42,361 \\
\hline & 90 & 10 & - & - & - & - & - & 30 & 1,022 & 39,067 \\
\hline & 85 & 15 & - & - & - & - & - & 30 & 1,022 & 30,465 \\
\hline & 80 & 20 & - & - & - & - & - & 30 & 1,022 & 33,348 \\
\hline \multirow[t]{12}{*}{$\begin{array}{l}\text { Chang et al. } \\
\text { [45] }\end{array}$} & 100 & - & - & - & - & - & - & 10 & 0,209 & 2,800 \\
\hline & 90 & - & 10 & - & - & - & - & 10 & 0,209 & 2,200 \\
\hline & 80 & - & 20 & - & - & - & - & 10 & 0,209 & 2,200 \\
\hline & 100 & - & - & - & - & - & - & 20 & 0,209 & 5,000 \\
\hline & 90 & - & 10 & - & - & - & - & 20 & 0,209 & 3,600 \\
\hline & 80 & - & 20 & - & - & - & - & 20 & 0,209 & 3,500 \\
\hline & 100 & - & - & - & - & - & - & 30 & 0,209 & 5,900 \\
\hline & 90 & - & 10 & - & - & - & - & 30 & 0,209 & 4,700 \\
\hline & 80 & - & 20 & - & - & - & - & 30 & 0,209 & 4,700 \\
\hline & 100 & - & - & - & - & - & - & 10 & 0,419 & 4,700 \\
\hline & 90 & - & 10 & - & - & - & - & 10 & 0,419 & 3,900 \\
\hline & 80 & - & 20 & - & - & - & - & 10 & 0,419 & 3,100 \\
\hline
\end{tabular}


TABLE 2: Continued.

\begin{tabular}{|c|c|c|c|c|c|c|c|c|c|c|}
\hline Reference & UHMWPE & $\begin{array}{c}\mathrm{ZnO} \\
\text { (wt.\%) }\end{array}$ & $\begin{array}{l}\text { Zeolite } \\
\text { (wt.\%) }\end{array}$ & $\begin{array}{c}\text { CNT } \\
\text { (wt.\%) }\end{array}$ & $\begin{array}{c}\text { CF } \\
\text { (wt.\%) }\end{array}$ & $\begin{array}{c}\mathrm{GO} \\
\text { (wt.\%) }\end{array}$ & $\begin{array}{c}\text { Wollastonite } \\
\text { (wt.\%) }\end{array}$ & $\begin{array}{c}\text { Load } \\
(\mathrm{N})\end{array}$ & $\begin{array}{c}\text { Sliding speed } \\
(\mathrm{m} / \mathrm{s})\end{array}$ & $\begin{array}{c}\text { Volume loss } \\
\left(\mathrm{mm}^{3}\right)\end{array}$ \\
\hline & 100 & - & - & - & - & - & - & 20 & 0,419 & 6,500 \\
\hline & 90 & - & 10 & - & - & - & - & 20 & 0,419 & 6,000 \\
\hline & 80 & - & 20 & - & - & - & - & 20 & 0,419 & 5,200 \\
\hline & 100 & - & - & - & - & - & - & 30 & 0,419 & 8,100 \\
\hline & 90 & - & 10 & - & - & - & - & 30 & 0,419 & 7,900 \\
\hline & 80 & - & 20 & - & - & - & - & 30 & 0,419 & 6,200 \\
\hline & 100 & - & - & - & - & - & - & 10 & 0,838 & 8,000 \\
\hline & 90 & - & 10 & - & - & - & - & 10 & 0,838 & 5,900 \\
\hline & 80 & - & 20 & - & - & - & - & 10 & 0,838 & 5,000 \\
\hline & 100 & - & - & - & - & - & - & 20 & 0,838 & 9,800 \\
\hline & 90 & - & 10 & - & - & - & - & 20 & 0,838 & 9,000 \\
\hline & 80 & - & 20 & - & - & - & - & 20 & 0,838 & 7,000 \\
\hline & 100 & - & - & - & - & - & - & 30 & 0,838 & 11,000 \\
\hline & 90 & - & 10 & - & - & - & - & 30 & 0,838 & 10,500 \\
\hline & 80 & - & 20 & - & - & - & - & 30 & 0,838 & 8,900 \\
\hline \multirow[t]{4}{*}{ Zoo et al. [18] } & 100 & - & - & - & - & - & - & 5 & 0,300 & 0,376 \\
\hline & 99,9 & - & - & 0,1 & - & - & - & 5 & 0,300 & 0,268 \\
\hline & 99,8 & - & - & 0,2 & - & - & - & 5 & 0,300 & 0,134 \\
\hline & 99,5 & - & - & 0,5 & - & - & - & 5 & 0,300 & 0,021 \\
\hline \multirow[t]{6}{*}{$\begin{array}{l}\text { Dangsheng } \\
{[14]}\end{array}$} & 100 & - & - & - & - & - & - & 196 & 0,420 & 1,820 \\
\hline & 95 & - & - & - & 5 & - & - & 196 & 0,420 & 1,400 \\
\hline & 90 & - & - & - & 10 & - & - & 196 & 0,420 & 1,350 \\
\hline & 85 & - & - & - & 15 & - & - & 196 & 0,420 & 1,110 \\
\hline & 80 & - & - & - & 20 & - & - & 196 & 0,420 & 0,730 \\
\hline & 70 & - & - & - & 30 & - & - & 196 & 0,420 & 0,590 \\
\hline \multirow[t]{7}{*}{ Tai et al. [46] } & 100 & - & - & - & - & - & - & 5 & 0,090 & 0,043 \\
\hline & 99,9 & - & - & - & - & 0,1 & - & 5 & 0,090 & 0,038 \\
\hline & 99,7 & - & - & - & - & 0,3 & - & 5 & 0,090 & 0,033 \\
\hline & 99,3 & - & - & - & - & 0,7 & - & 5 & 0,090 & 0,028 \\
\hline & 99 & - & - & - & - & 1 & - & 5 & 0,090 & 0,028 \\
\hline & 98 & - & - & - & - & 2 & - & 5 & 0,090 & 0,026 \\
\hline & 97 & - & - & - & - & 3 & - & 5 & 0,090 & 0,025 \\
\hline \multirow[t]{8}{*}{ Tong et al. [47] } & 100 & - & - & - & - & - & - & 120 & 0,530 & 1,73 \\
\hline & 95 & - & - & - & - & - & 5 & 120 & 0,530 & 1,31 \\
\hline & 90 & - & - & - & - & - & 10 & 120 & 0,530 & 1,2 \\
\hline & 85 & - & - & - & - & - & 15 & 120 & 0,530 & 1,58 \\
\hline & 80 & - & - & - & - & - & 20 & 120 & 0,530 & 1,8 \\
\hline & 90 & - & - & - & - & - & 10 & 40 & 0,530 & 0,25 \\
\hline & 90 & - & - & - & - & - & 10 & 80 & 0,530 & 0,7 \\
\hline & 90 & - & - & - & - & - & 10 & 160 & 0,530 & 2,28 \\
\hline
\end{tabular}




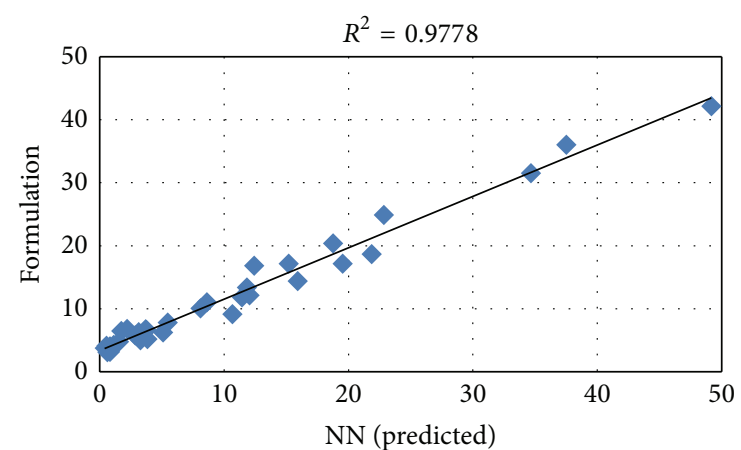

(a)

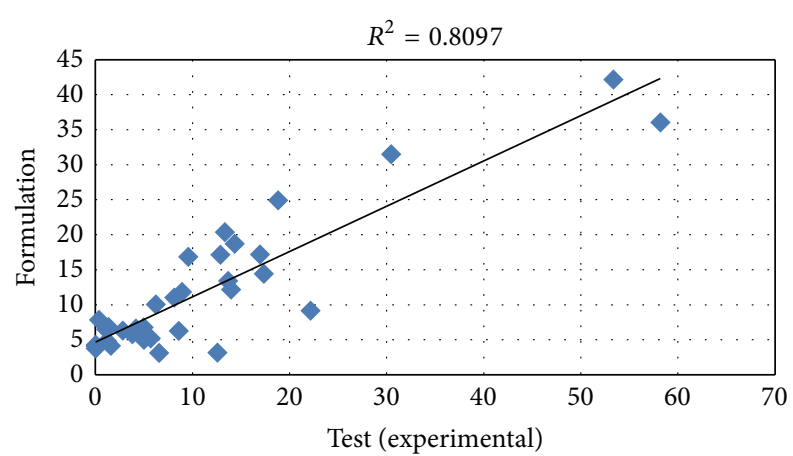

(b)

FIGURE 7: Correlation of (a) NN and formulation and (b) NN and testing set.

under $10 \mathrm{~N}$ load at a sliding speed of $0.033 \mathrm{~m} / \mathrm{s}$ was determined as $3.093 \mathrm{~mm}^{3}$. In the same experimental conditions, to decrease the wear volume loss to $1.992 \pm 0.165 \mathrm{~mm}^{3}$, the $1 \mathrm{wt} . \%$ of zeolite with the size of $45 \mu \mathrm{m}$ was added according to the NN model theoretically. As a result, the wear volume loss formulation of UHMWPE was evaluated and the two volume loss values were calculated by using this formulation. Additionally, the correlation coefficients of the proposed equations were also evaluated. The correlations of $\mathrm{NN}$, formulation, and experimental data were given in Figure 7.

It is clear that $R^{2}$ values of formulation and $\mathrm{NN}$ model and formulation and experimental results are 0.9778 and 0.8097 , respectively. This means that the proposed NN model (formulation) can predict the volume loss of the composites with $80.97 \%$ accuracy.

\section{Conclusion}

This study proposes an approach of artificial neural network modeling for the wear volume loss in the prediction of UHMWPE composites with different fibers and particles and in various operating parameters. The proposed NN model shows good agreement with the experimental results. Therefore, the explicit mathematical function was derived from ANN models. In the accuracy of the well-trained ANN model, all $R^{2}$ values for training, testing, and formulation are bigger than 0.80 and the predicted model is of a high reliability rate. The mean absolute error for predicted values does not exceed $4.1 \%$. The sensitivity analysis of the developed NN model demonstrated that sliding speed and applied load are the significant variables in affecting the volume loss. Hence, it was concluded that ANN is a successful and advantageous analytical tool for determining the properties of UHMWPE composites with considerable saving in cost and time.

\section{Appendix}

See Table 2.

\section{Conflict of Interests}

The authors declare that there is no conflict of interests regarding the publication of this paper.

\section{References}

[1] Z.-M. Huang, Y.-Z. Zhang, M. Kotaki, and S. Ramakrishna, "A review on polymer nanofibers by electrospinning and their applications in nanocomposites," Composites Science and Technology, vol. 63, no. 15, pp. 2223-2253, 2003.

[2] Y. Kim, H. Lee, S. Park, and X. Zhang, "Stress relaxation test of molding compound for MEMS packaging," in Proceedings of the 13th InterSociety Conference on Thermal and Thermomechanical Phenomena in Electronic Systems (ITherm '12), pp. 290-296, IEEE, San Diego, Calif, USA, June 2012.

[3] A. S. Luyt, J. A. Molefi, and H. Krump, "Thermal, mechanical and electrical properties of copper powder filled lowdensity and linear low-density polyethylene composites," Polymer Degradation and Stability, vol. 91, no. 7, pp. 1629-1636, 2006.

[4] L. Woo, M. T. K. Ling, S. Y. Ding, and S. P. Westphal, "Effect of ionizing radiation on the thermal oxidative stability of medical polymers," Thermochimica Acta, vol. 324, no. 1-2, pp. 179-185, 1998.

[5] S. Devasahayam and P. Yarlagadda, "Mechanics of polyropylene-seed-coat-fibres composites andpolyropylenewood fibres composites-a comparative study," Procedia Engineering, vol. 97, pp. 1915-1928, 2014.

[6] B. S. Shim, J. Starkovich, and N. Kotov, "Multilayer composites from vapor-grown carbon nano-fibers," Composites Science and Technology, vol. 66, no. 9, pp. 1171-1178, 2006.

[7] W. S. Lee and J. Yu, "Comparative study of thermally conductive fillers in underfill for the electronic components," Diamond and Related Materials, vol. 14, no. 10, pp. 1647-1653, 2005.

[8] V. Choudhary and A. Gupta, "Polymer/carbon nanotube nanocomposites," in Carbon Nanotubes-Polymer Nanocomposites, chapter 4, pp. 65-90, InTech, Rijeka, Croatia, 2011.

[9] W. Zhao, H. Wang, H. Tang, and G. Chen, "Facile preparation of epoxy-based composite with oriented graphite nanosheets," Polymer, vol. 47, no. 26, pp. 8401-8405, 2006.

[10] S. Kemaloglu, G. Ozkoc, and A. Aytac, "Properties of thermally conductive micro and nano size boron nitride reinforced silicon 
rubber composites," Thermochimica Acta, vol. 499, no. 1-2, pp. 40-47, 2010.

[11] X.-L. Xie, Y.-W. Mai, and X.-P. Zhou, "Dispersion and alignment of carbon nanotubes in polymer matrix: a review," Materials Science and Engineering R: Reports, vol. 49, no. 4, pp. 89-112, 2005.

[12] S. M. Kurtz, UHMWPE Biomaterials Handbook: Ultra High Molecular Weight Polyethylene in Total Joint Replacement and Medical Devices, Elsevier Science, 2009.

[13] P. S. M. Barbour, M. H. Stone, and J. Fisher, "A study of the wear resistance of three types of clinically applied UHMWPE for total replacement hip prostheses," Biomaterials, vol. 20, no. 22, pp. 2101-2106, 1999.

[14] X. Dangsheng, "Friction and wear properties of UHMWPE composites reinforced with carbon fiber," Materials Letters, vol. 59, no. 2-3, pp. 175-179, 2005.

[15] K. Plumlee and C. J. Schwartz, "Improved wear resistance of orthopaedic UHMWPE by reinforcement with zirconium particles," Wear, vol. 267, no. 5-8, pp. 710-717, 2009.

[16] G. Guofang, Y. Huayong, and F. Xin, "Tribological properties of kaolin filled UHMWPE composites in unlubricated sliding," Wear, vol. 256, no. 1-2, pp. 88-94, 2004.

[17] D. Xiong, J. Lin, D. Foan, and Z. Jin, "Wear of nano$\mathrm{TiO}_{2} /$ UHMWPE composites radiated by gamma ray under physiological saline water lubrication," Journal of Materials Science: Materials in Medicine, vol. 18, no. 11, pp. 2131-2135, 2007.

[18] Y.-S. Zoo, J.-W. An, D.-P. Lim, and D.-S. Lim, "Effect of carbon nanotube addition on tribological behavior of UHMWPE," Tribology Letters, vol. 16, no. 4, pp. 305-310, 2004.

[19] H. K. Durmuş, E. Özkaya, and C. Meriç, “The use of neural networks for the prediction of wear loss and surface roughness of AA 6351 aluminium alloy," Materials \& Design, vol. 27, no. 2, pp. 156-159, 2006.

[20] H. Çetinel, H. Öztürk, E. Çelik, and B. Karlik, "Artificial neural network-based prediction technique for wear loss quantities in Mo coatings," Wear, vol. 261, no. 10, pp. 1064-1068, 2006.

[21] Z. Zhang, K. Friedrich, and K. Velten, "Prediction on tribological properties of short fibre composites using artificial neural networks," Wear, vol. 252, no. 7-8, pp. 668-675, 2002.

[22] A. P. Vassilopoulos, E. F. Georgopoulos, and V. Dionysopoulos, "Artificial neural networks in spectrum fatigue life prediction of composite materials," International Journal of Fatigue, vol. 29, no. 1, pp. 20-29, 2007.

[23] H. I. Kurt and M. Oduncuoglu, "Formulation of the effect of different alloying elements on the tensile strength of the in situ Al- $\mathrm{Mg}_{2}$ Si composites," Metals, vol. 5, no. 1, pp. 371-382, 2015.

[24] H. I. Kurt and M. Oduncuoglu, "Effects of temperature, time, magnesium, and copper on the wettability of $\mathrm{Al} / \mathrm{TiC}$ system," Mathematical Problems in Engineering. In press.

[25] K. Venkata Rao, B. S. N. Murthy, and N. Mohan Rao, "Prediction of cutting tool wear, surface roughness and vibration of work piece in boring of AISI 316 steel with artificial neural network," Measurement, vol. 51, no. 1, pp. 63-70, 2014.

[26] L. A. Gyurova and K. Friedrich, "Artificial neural networks for predicting sliding friction and wear properties of polyphenylene sulfide composites," Tribology International, vol. 44, no. 5, pp. 603-609, 2011.

[27] X. Li, Y. Zhu, and G. Xiao, "Application of artificial neural networks to predict sliding wear resistance of Ni-TiN nanocomposite coatings deposited by pulse electrodeposition," Ceramics International, vol. 40, no. 8, part A, pp. 11767-11772, 2014.
[28] S. S. Haykin, Neural Networks: A Comprehensive Foundation, Prentice Hall, 1999.

[29] M. Yurdakul and H. Akdas, "Modeling uniaxial compressive strength of building stones using non-destructive test results as neural networks input parameters," Construction and Building Materials, vol. 47, pp. 1010-1019, 2013.

[30] R. Hecht-Nielsen, Neurocomputing, Addison-Wesley, 1990.

[31] D. E. Rumelhart, G. E. Hinton, and R. J. Williams, "Learning internal representations by error propagation," in Parallel Distributed Processing: Explorations in the Microstructure of Cognition, E. R. David, L. M. James, and C. P. R. Group, Eds., vol. 1, pp. 318-362, MIT Press, 1986.

[32] A. Cevik, M. A. Kutuk, A. Erklig, and I. H. Guzelbey, "Neural network modeling of arc spot welding," Journal of Materials Processing Technology, vol. 202, no. 1-3, pp. 137-144, 2008.

[33] R. Roiger and M. Geatz, Data Mining: A Tutorial-Based Primer, Addison-Wesley, 2003.

[34] D. T. Larose, "Neural Networks," in Discovering Knowledge in Data, pp. 128-146, John Wiley \& Sons, 2005.

[35] B. P. Chang, H. M. Akil, M. G. Affendy, A. Khan, and R. B. M. Nasir, "Comparative study of wear performance of particulate and fiber-reinforced nano- $\mathrm{ZnO} /$ ultra-high molecular weight polyethylene hybrid composites using response surface methodology," Materials \& Design, vol. 63, pp. 805-819, 2014.

[36] A. M. Hassan, A. Alrashdan, M. T. Hayajneh, and A. T. Mayyas, "Prediction of density, porosity and hardness in aluminumcopper-based composite materials using artificial neural network," Journal of Materials Processing Technology, vol. 209, no. 2, pp. 894-899, 2009.

[37] Y. Sun, W. D. Zeng, X. M. Zhang, Y. Q. Zhao, X. Ma, and Y. F. Han, "Prediction of tensile property of hydrogenated Ti600 titanium alloy using artificial neural network," Journal of Materials Engineering and Performance, vol. 20, no. 3, pp. 335340, 2011.

[38] M. Sudheer, R. Prabhu, K. Raju, and T. Bhat, "Effect of filler content on the performance of epoxy/PTW composites," Advances in Materials Science and Engineering, vol. 2014, Article ID 970468, 11 pages, 2014.

[39] A. Gupta, A. Kumar, A. Patnaik, and S. Biswas, "Effect of different parameters on mechanical and erosion wear behavior of bamboo fiber reinforced epoxy composites," International Journal of Polymer Science, vol. 2011, Article ID 592906, 10 pages, 2011.

[40] A. Dolata-Grosz and J. Wieczorek, "Tribological properties of hybrid composites containing two carbide phases," Archives of Materials Science and Engineering, vol. 28, no. 3, pp. 149-155, 2007.

[41] K. V. Mahendra and K. Radhakrishna, "Characterization of stir cast $\mathrm{Al}-\mathrm{Cu}$-(fly ash $+\mathrm{SiC}$ ) hybrid metal matrix composites," Journal of Composite Materials, vol. 44, no. 8, pp. 989-1005, 2010.

[42] S. Basavarajappa, G. Chandramohan, K. Mukund, M. Ashwin, and M. Prabu, "Dry sliding wear behavior of Al 2219/SiCpGr hybrid metal matrix composites," Journal of Materials Engineering and Performance, vol. 15, no. 6, pp. 668-674, 2006.

[43] A. Cevik and I. H. Guzelbey, "Neural network modeling of strength enhancement for CFRP confined concrete cylinders," Building and Environment, vol. 43, no. 5, pp. 751-763, 2008.

[44] B.-P. Chang, H. M. Akil, and R. B. M. Nasir, "Comparative study of micro- and nano-ZnO reinforced UHMWPE composites under dry sliding wear," Wear, vol. 297, no. 1-2, pp. 1120-1127, 2013. 
[45] B. P. Chang, H. M. Akil, and R. M. Nasir, "Mechanical and tribological properties of Zeolite-reinforced UHMWPE composite for implant application," Procedia Engineering, vol. 68, pp. 8894, 2013.

[46] Z. Tai, Y. Chen, Y. An, X. Yan, and Q. Xue, "Tribological behavior of UHMWPE reinforced with graphene oxide nanosheets," Tribology Letters, vol. 46, no. 1, pp. 55-63, 2012.

[47] J. Tong, Y. Ma, and M. Jiang, "Effects of the wollastonite fiber modification on the sliding wear behavior of the UHMWPE composites," Wear, vol. 255, no. 1-6, pp. 734-741, 2003. 

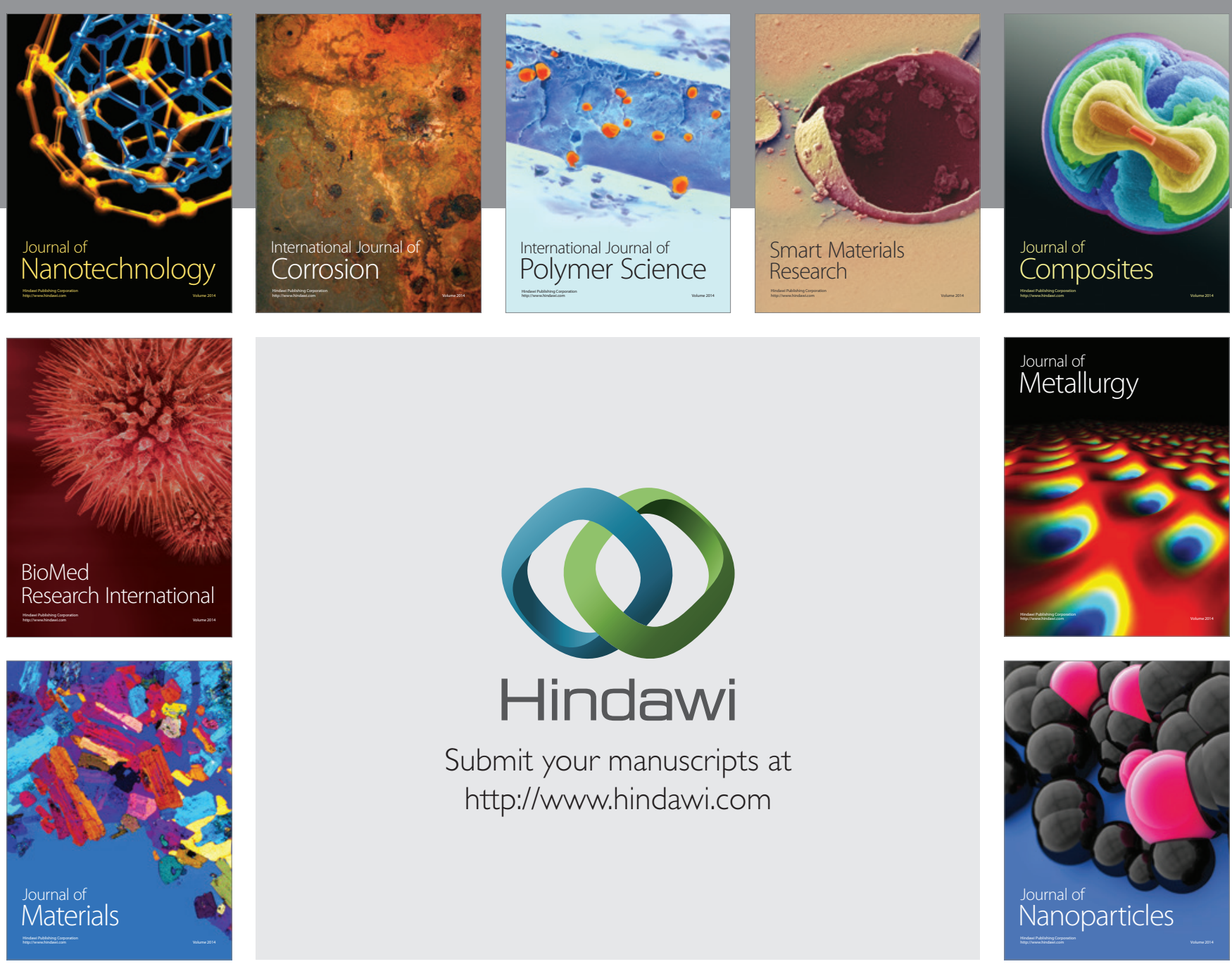

Submit your manuscripts at http://www.hindawi.com
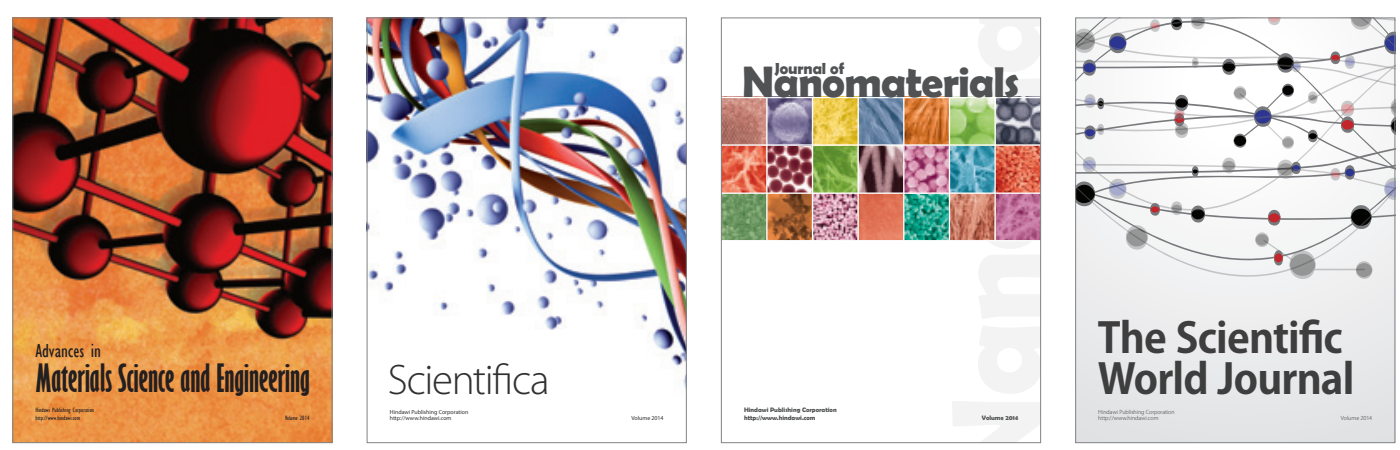

\section{The Scientific World Journal}
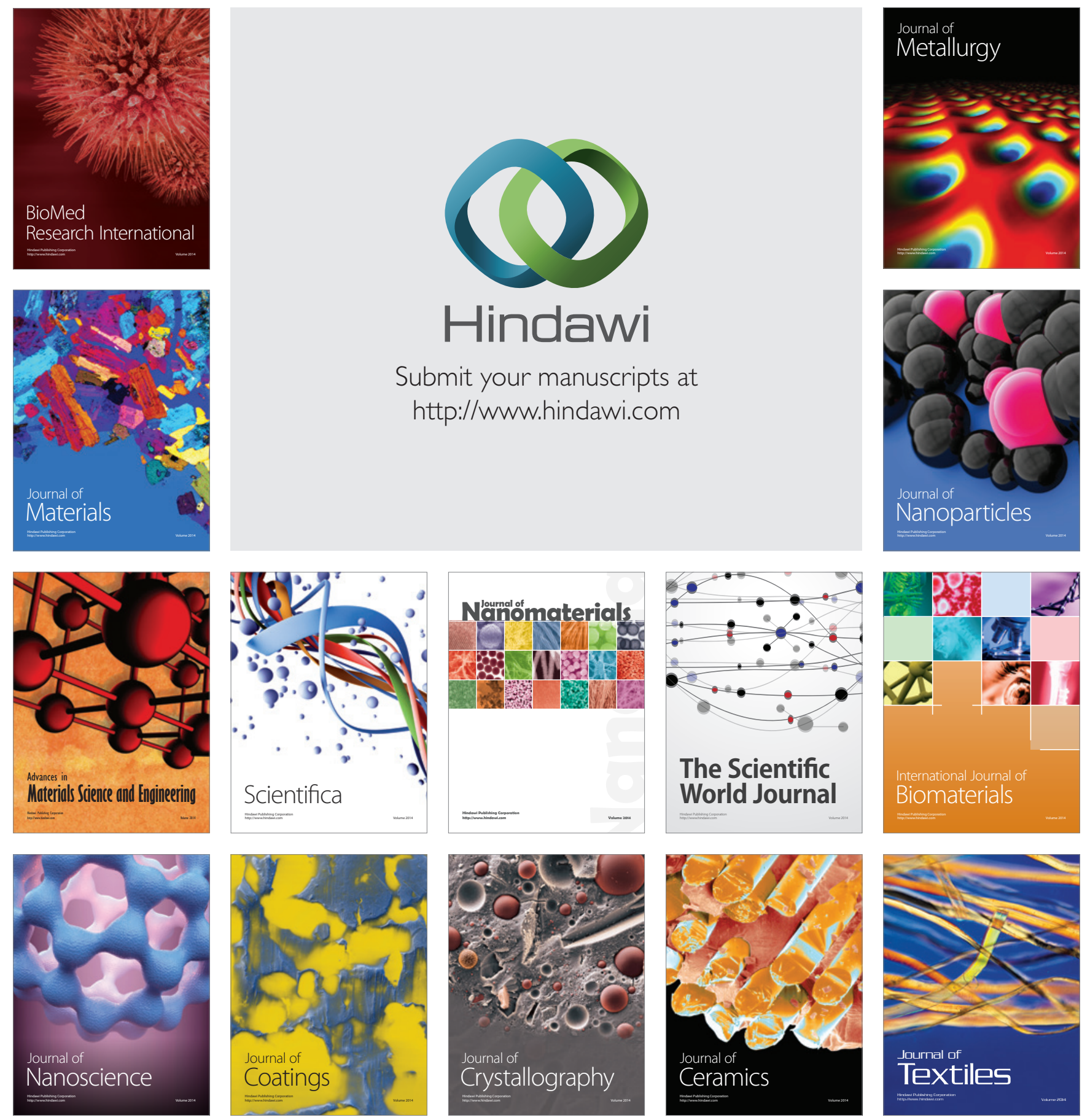